\title{
Psychological Stress and Nursing Intervention of Sick Children
}

\author{
Yiying Chen ${ }^{1}$, Feiyan $\mathrm{Li}^{2 *}$ \\ ${ }^{1}$ Tunchang People's Hospital, Tunchang County, Hainan Province, China \\ ${ }^{2}$ Hainan General Hospital, Haikou, China \\ Email: ^g2002m@163.com
}

How to cite this paper: Chen, Y.Y. and $\mathrm{Li}$, F.Y. (2021) Psychological Stress and Nursing Intervention of Sick Children. International Journal of Clinical Medicine, 12, 202-210.

https://doi.org/10.4236/ijcm.2021.125019

Received: April 25, 2021

Accepted: May 24, 2021

Published: May 27, 2021

Copyright $\odot 2021$ by author(s) and Scientific Research Publishing Inc. This work is licensed under the Creative Commons Attribution International License (CC BY 4.0).

http://creativecommons.org/licenses/by/4.0/ (c) (i) Open Access

\begin{abstract}
Holistic nursing is guided by modern nursing concept and framed by nursing procedures, providing high quality nursing according to patients' psychological, physiological, social and cultural needs. To develop holistic nursing in pediatrics is to develop nursing services for the purpose of satisfying the various clinical needs and psychological nursing of children. It is of great significance to establish holistic nursing concept, provide high quality nursing service for hospitalized children, and take targeted psychological intervention to alleviate their adverse psychological stress, which can improve treatment compliance and clinical efficacy, and shorten the length of hospital stay. In this paper, scientific and effective psychological nursing stress intervention means are used to improve the psychological anti-stress level of hospitalized children, and nursing intervention means are put forward, contribute to the maintenance of children's mental health and the development of children's mental health work and also to provide a theoretical basis for the intervention and treatment of children with psychological stress.
\end{abstract}

\section{Keywords}

Sick Children, Psychological Stress, Nursing, Psychological Intervention

\section{Introduction}

In the process of interaction between the organism and the environment, children form a variety of conditioned reflexes based on unconditional reflexes, thus forming the initial psychological and psychological structure, which is the product of the interaction between the individual's special heredity and the special environment [1]. Functional stress in children mainly presents serious disorders in thinking, cognition, perception, emotion, behavior and other aspects, which 
has a great impact on mental and physical health. It is often ignored by family members due to morbidity, atypical clinical manifestations and no special physical signs. It is found that the factors leading to children's psychological problems include diseases, bad social environment (such as car accidents), bad family environment and educational attitude, etc. [2]. Psychological nursing is a clinical nursing method that applies psychological knowledge and technology to solve children's psychological problems, improve children's confidence in life and promote their mental health [3] for existing and potential psychological problems of children. This text intends to explore the causes of the occurrence and development of hospitalized children's stress, and improve the level of children's psychological anti-stress with scientific and effective psychological nursing stress intervention means, which is expected to provide valuable data for the intervention of children's psychological stress and provide scientific basis for the exploration of children's psychological clinical intervention measures.

\section{Physiological and Psychological Characteristics of Children}

Children are in the process of growth and development, and their psychological and spiritual activities are also developing along with it. Due to their young age and lack of knowledge and understanding of the disease, their psychological activities change rapidly with the change of treatment situation, and their attention shifts quickly, and their emotional expression is obvious, exposed and simple [4]. Surgical bleeding, trauma and other stimuli will cause a strong psychological reaction to children. Psychologists have found that from birth to 3 months, infants can have 6 emotional reactions, including desire, joy, disgust, anger, shock and boredom. Babies under 6 months have no worries about leaving their parents, while children between 6 months and 4 years old have the greatest emotional disturbance when they are hospitalized [5]. Studies have also shown that anesthesia, especially during the induction phase, has been identified as an underlying cause of trauma. In a study conducted by Guarino M [6], 54\% of children showed abnormal behaviors 2 weeks after surgery, of which $20 \%$ continued to 6 months after surgery and $7.3 \%$ continued to 1 year after surgery. Some psychosomatic diseases, such as stuttering, night terrors, enuresis, and bronchial asthma, can be caused by panic in children. The following are some common preoperative psychological states of children.

Fear is the most common reaction of children, mainly manifested as crying, refusal to food, sleep disturbance, refusal of examination and treatment, and refusal of surgery. Firstly, it is because the children are exposed to a strange environment; secondly, the pain of the disease and various diagnosis and treatment procedures bring adverse stimulation to the children [5]. Some researchers suggest that nursing staff should carry picture books, small toys or ornaments with them to distract children's attention and gain their trust and cooperation [7].

Dependence is manifested as behavioral degeneration. They do not do what 
they can do and are completely dependent on their parents and caregivers. Such protective behavior also strengthens their dependence psychology. They are easily excited, wailing and willful, and love to lose temper [8]. Reasonable requirements of children should be satisfied as far as possible, and explanations should be given for those who cannot be satisfied [9]. Young children are most afraid of being separated from their parents. If parents are allowed to accompany them during preoperative preparation, it will be the best comfort for children.

The psychological development of children with anxiety is not complete, and the main reasons for the anxiety of children during the perioperative period are the separation of parents and family members and the fear of unfamiliar environment [10]. Older children (mostly school-age children) are very concerned about their disease, treatment to be received, body changes during and after the operation, the effect of the operation, etc., and they show anxiety, anxiety, anger, etc. [11]. For such children, we should have patience and full respect and understanding, give good guidance, tell them the condition at the same time, but also let them face the next treatment with a good attitude.

Pessimistic depression such children are mostly introverted, unwilling to communicate with others, and think that they are incurable. Performance for the words of the act alone, all around the loss of interest, serious people can produce the idea of suicide. For such children, more need the love and responsibility of medical staff, psychological counseling, establish a sense of trust, establish confidence to overcome the disease.

\section{Warm and Thoughtful Care}

It is found that the factors that lead to children's psychological problems include diseases, bad social environment, bad family environment and bad educational attitude. If the body is affected by the outside the body, a variety of pathogenic factors, and develop education errors or bad environment, the effect of disorder in the brain function, psychological activity cannot smoothly self adjusting, the cognition, emotion, thinking, behavior and activity will appear different degree of obstacles, which leads to the wrong understanding and judgment, and cannot correctly treat the objective things.

Children are hospitalized and come to an unfamiliar hospital from a familiar and warm family living environment. At the sight of the medical staff wearing white coats and the furnaces of the sick room, my mental state changed from relaxed and happy to nervous and fearful. Especially after the child is hospitalized, the mother cannot accompany the child to be hospitalized, the child subjectively do not want to be hospitalized. This situation is more prominent among preschool children and rural children. Therefore, the nurse should use kind words to contact and communicate with the children, can take the children to see other children in hospital when the injection, medicine, treatment, gradually make the child gradually eliminate tension. In addition, from the careful care of life, let the children who have been in hospital for a long time take the initiative to close to 
new patients, and play with them, read comics, so that they feel the warmth of the new environment and the trust of the nurse, as soon as possible to adapt to the hospital living environment, with treatment, as soon as possible to return to health.

The children came from different living environments and formed their own personality characteristics. And because of the level of education = different, so that their intelligence development is also very different. Most of the children from cities grow up in kindergartens. They have good intelligence, strong understanding ability and quick adaptation to the environment. However, the children from rural areas showed more timid, withdrawn and reluctant to talk when they were first admitted to hospital. But children have strong ability to imitate and eager to learn the psychological characteristics. They observe and accept new things quickly. For the children in New Hospital, according to these characteristics, we carry out targeted inspiration and induction, organize games and tell stories. When the child is examined and treated for the first time, let the child see their child's performance in the examination and treatment process, praise and encourage the brave and cooperative children, the nurse speaks with the child clearly, eliminate the children's fear, let them accept the treatment and examination happily. I once nursed a five-year-old female rural child with thrombocytopenic purpura. At the beginning of treatment in the hospital, she cried, refused to be fed, and twice quietly ran out of the ward, terrified. I began by telling her stories, showing her children who were being treated, praising her for her bravery, and saying that she was strong enough to stay in the hospital without her mother. She did not cry, but with a tender voice told me, "aunt, I am not afraid, injection do not cry" I helped her comb her hair, wash her face, she trusted me. After a period of time to ask the efforts, so that she gradually adapt to the hospital life, not only can cooperate with the treatment, but also cultivate the ability to live independently, and doctors and nurses to establish a deep relationship.

\section{Instruct Children to Accept the Treatment Diet to Lay a Foundation for Treatment}

The children come from different family environments and have their own living and eating habits. The nurse should give guidance on the treatment and diet according to the different conditions of the children and let them accept it. Nephritis, kidney disease in children, to limit the intake of sodium, the need to give a low-salt or no-salt diet, children are not easy to accept the initial, because the food is tasteless and lead to a loss of appetite. In this regard, preschool and school-age children can tell them the relationship between clear diet and treatment, but also to give some vinegar or sugar for appropriate adjustment, and encourage children to eat more fruit, high protein food. Most children love sweets, and it is not easy to strictly control the intake of sugar for diabetic children. Therefore, on the one hand, it is necessary to tell children the harm of eat- 
ing sugar on the disease, and on the other hand, a small amount of sweet food can be given appropriately. After a period of hospitalization, the vast majority of children can consciously obey the treatment diet, to lay a good foundation for treatment.

The regular life of the hospital can make the children get rid of some free and undisciplined, capricious, bad habits of eating snacks. After the hospital, the children are placed in a collective living environment, eating, sleeping, learning and playing together, and can influence each other. We give education and guidance from the positive perspective according to the psychological characteristics of children with simple thoughts and strong self-esteem. For example, there is a 7-year-old boy suffering from nephritis, who is pampered by his parents at home. He is headstrong and likes to eat snacks. When they entered the new hospital, they did not listen to anyone. We will pay attention to observe his character characteristics, found that he has the ability to observe things, is willing to help the advantages of small friends, so pay attention to praise his every bit of progress in the children, from life, diet to guide him to correct shortcomings, cultivate good habits, so that he has made significant progress in all aspects.

\section{Pediatric Nurses Should Have Good Nursing Skills}

Pediatric nurses are required to keep improving on all technical operations, and the movements should be stable, accurate, light and fast [12]. When children are worried about their condition and in an emotional state, the nursing staff can according to the actual condition of children, and consider the psychological acceptance of children, their condition with concise and clear sentences described, so that children can better understand their own condition. The caregiver could say, "There's something in your body that's not clean, and the doctor will clean it up while you're sleeping, and it won't hurt like a needle, you just need to sleep and you'll be fine when you wake up." Through this simple and popular sentence, children can understand their own conditions, gradually reduce negative emotions, so as to better cooperate with the nursing staff to carry out various work. In the process of child care, because children's own heart quality is not strong, is easy to produce fear, nervousness, and so on the care of nursing staff in the language communication skills, must notice when children from the psychological perspective, relieve the tension and fear, let it can work with their own care, so as to obtain better nursing effect, promote the healthy growth of children.

Through clinical observation of $\mathrm{L}$, we have realized that children's psychological development is influenced by external education. Most children have developed the ability to perceive emotions since infancy, and they are accustomed to warm and gentle voice and warm and considerate behavior. The treatment of children varies according to age and disease. Neonates and infants have weak skin perception. When making injection and venipuncture, the action should be light and fast, and the injection should be successful, and the crying caused by 
stimulation should be minimized. For preschool and school-age children, with the improvement of their brain thinking ability, their sensitivity to pain is enhanced [13]. Corresponding psychotherapy can be given, such as suggestive therapy, educational therapy, etc. Before the treatment, patiently explain the operation process and purpose to the children, so that the children maintain a good psychological state; And with a steady working attitude and excellent basic skills, to obtain the trust and cooperation of children, to achieve the purpose of treatment. Such as penicillin allergy test, intramuscular injection, venipuncture, aerosol inhalation and other treatment, the first time for children are not accepted. You can first let the children who have been treated demonstrate; when penicillin injection is made in the large ward, attention should be paid to the children who have been in hospital for a long time, and encouragement should be given actively before injection. During injection, the method of fast needle insertion, slow drug pushing and fast needle pulling is adopted [14]. And children with laughing, distraction, eliminate tension. Through clinical practice, we have received good results, most of the children consciously, actively accept treatment. For some children who cannot be well coordinated on treatment, we will be patient to induce; For example, a 9-year-old boy with cirrhosis ascites, because of a long time of treatment in the other hospital, at the beginning of the hospital, the intramuscular injection of penicillin produced fear, crying and resistance, his mother repeatedly coexhorted, lost his temper is ineffective. Therefore, we first gave a sick child treatment, comfort and encourage him, let his mood slowly stabilize, and let the sick children in the ward to encourage him, and finally successfully accepted the treatment.

\section{Master the Psychological Changes of Patients, Do a Good Job in Clinical Observation and Nursing}

Children have weak resistance to disease, rapid change of disease, and poor expression ability; Unable to specifically describe their own symptoms and discomfort after illness. In particular, infants often show crying and irritability. Therefore, as a pediatric nurse, we should learn to carefully observe the changes in the condition of children and assist doctors to provide the basis for diagnosis.

Because the development of children's nervous system is not complete, the excitatory focus under the cerebral cortex is easy to spread, and children with different age, disease and individual differences and other factors, a variety of different responses to hospitalization and physiological and psychological changes. For example, some children show the insecurity of leaving their loved ones at the beginning, mental depression, fear and silence, behavioral degeneration, decreased appetite and even refusal to eat. Some older children can also suffer from disease, show negative and pessimistic mood, and even refuse to accept treatment. Therefore, the nurse should have the same noble sentiment as the mother loves the child, from the perspective of children to find problems; In mind, in life, always give guidance and care [15]. Such as more contact and con- 
versation with them, let other children take the initiative to close to them, patrol the ward at night, pay attention to their cover to prevent catching cold; Do not let them carry their own soup or porridge to avoid being scalded. Teach children to help each other so that they feel warm and loved in the hospital as well as at home.

The effect of some drugs can also make children produce different abnormal psychology. For example, for the child that changes nephritis, kidney disease because take big dose hormone for a long time, they show feeling fragile, easy excited, temper is irritable wait for a characteristic. Encounter quarrel between children or not happy, on the cry to make a scene, temper, for such children, we will send an old nurse organization they learn, play games, participate in some light labor, such as taking turns on duty sweeping the floor, wipe the table and so on. Choose a monitor among them and have regular meetings. When there are conflicts, education guides them to solve them by themselves, so that they are placed in a comfortable and stable environment, reducing adverse stimuli from the outside world, and enriching their spiritual life [16].

A competent pediatric nurse should not only master medical knowledge and nursing skills, but also carefully study and master the psychological and physiological characteristics of children. In clinical practice, observation and analysis of patients' psychological responses and targeted psychological nursing can effectively cooperate with clinical treatment and achieve the goal of early rehabilitation [17].

In conclusion, children's psychology is an open self-organizing structure, which has the characteristics of integrity, transformation and automatic adjustment.

\section{Conclusion}

Children's psychology, as an organic system structure, is the whole of the automatic adjustment of the transformation system. There are internal connections between individual psychological process and personality, between psychological process and personality, between consciousness and unconsciousness, and between social consciousness and individual consciousness. They are not the result of simple addition, but complex interdependence and mutual dependence. The whole of constraints, consciousness and personality are formed and developed in the development process of psychological activities. At the same time, the established consciousness and personality also offset the development of psychological process and subconsciousness. The development of children's psychology is a systematic process of continuous construction. The influence of a certain environmental stimulus not only plays a role in a certain aspect of individual psychology, but also plays a role in the whole psychology. At the same time, the individual psychological change is completed by the individual's automatic regulation, which is the automatic result of individual consciousness activities. In short [18] [19] [20] [21], whether it is the development of children's individual psy- 
chological process and personality, or the development of consciousness level and structure, they are all systematic processes. Although the theoretical framework of children's psychological stress is not strictly defined and the research field is not perfect, its significance to children's survival and development has prompted people to continue to study. There is still a long way to go to truly understand the nature of psychological stress, but fortunately we have made progress towards this goal.

\section{Conflicts of Interest}

The authors declare no conflicts of interest regarding the publication of this paper.

\section{References}

[1] Zhang, L.R. (2017) Clinical Effect Analysis of Psychological Nursing Implementation in Children Health Physical Examination. Modern Diagnosis and Therapy, 28, 2933-2934.

[2] Cheng, X. (2017) Evaluation of the Application Effect of Psychological Nursing in Children's Health Physical Examination. China Rural Health, No. 8, 74-77.

[3] Zhang, D.D. and Lin, X.B. (2016) Evaluation of the Application Effect of Psychological Nursing in Children Health Physical Examination. Journal of Mathematical Medicine and Pharmacy, 29, 905-906.

[4] Zhang, M.H. and Wang, S. (1997) The Application Experience of Psychological Nursing in Children Health Physical Examination. Journal of Qinghai Medical College, No. 4, 290-299.

[5] Rutski, J.R., Gaarden, T., Bremnes, R., et al. (2010) A Study of Coping in Long-Term Testicular Cancer Survivors. Psychology, Health \& Medicine, 15, 146-158. https://doi.org/10.1080/13548501003623955

[6] Guarino, M., Cheng, L., Cicala, M., et al. (2011) Progesterone Receptors and Serotonin Levels in Colon Epithelial Cells from Females with Slow Transit Constipation. Neurogastroenterology \& Motility, 23, 575. https://doi.org/10.1111/j.1365-2982.2011.01705.x

[7] Ye, F.P. (2014) Psychological Characteristics and Nursing Intervention of Parents of Adolescent Depression. Journal of Applied Clinical Medicine, 18, 112.

[8] Utrillas-Compaired, A., De la Torre-Escuredo, B.J., Tebar-Martinez, A.J., et al. (2014) Does Preoperative Psychologic Distress Influence Pain. Clinical Orthopaedics and Related Research, 472, 2457-2465. https://doi.org/10.1007/s11999-014-3570-5

[9] Waseem, H., Mazzamurro, R.S., Fisher, A.H., et al. (2018) Parental Satisfaction with Being Present in the Operating Room during the Induction of Anesthesia Prior to Pediatric Neurosurgical Intervention: A Qualitative Analysis. Journal of Neurosurgery Pediatrics, 21, 528-534. https://doi.org/10.3171/2017.10.PEDS17261

[10] Cui, X., Zhu, B., Zhao, J., et al. (2016) Parental State Anxiety Correlates with Preoperative Anxiety in Chinese Preschool. Journal of Pediatrics \& Child Health, 52, 649-655. https://doi.org/10.1111/jpc.13176

[11] Zhou, G.X. (2012) Nursing Intervention of Separation Anxiety in Children before Surgery. Journal of Nursing Science, 27, 80-81. 
[12] Millett, C.R. and Gooding, L.F. (2017) Comparing Active and Passive Distraction-Based Music Therapy Interventions on Preoperative Anxiety in Pediatric Patients and Their Caregivers. Journal of Music Therapy, 54, 460-478. https://doi.org/10.1093/jmt/thx014

[13] Liu, P.P., Sun, Y., Wu, C., et al. (2018) The Effectiveness of Transport in a Toy Car for Reducing Preoperative Anxiety in Preschool Children: A Randomised Controlled Prospective Trial. British Journal of Anaesthesia, 121, 438-444. https://doi.org/10.1016/j.bja.2018.02.067

[14] Ryu, J.H., Park, S.J., Park, J.W., et al. (2017) Randomized Clinical Trial of Immersive Virtual Reality Tour of the Operating Theatre in Children before Anaesthesia. British Journal of Surgery, 104, 1628-1633. https://doi.org/10.1002/bjs.10684

[15] Bailey, K.M., Bird, S.J., Mcgrath, P.J., et al. (2015) Preparing Parents to Be Present for Their Child's Anesthesia Induction: A Randomized Controlled Trial. Anesthesia \& Analgesia, 121, 1001-1010. https://doi.org/10.1213/ANE.0000000000000900

[16] Waseem, H., Mazzamurro, R.S., Fisher, A.H., et al. (2018) Parental Satisfaction with Being Present in the Operating Room during the Induction of Anesthesia Prior to Pediatric Neurosurgical Intervention: A Qualitative Analysis. Journal of Neurosurgery Pediatrics, 21, 528-534. https://doi.org/10.3171/2017.10.PEDS17261

[17] Wang, C. and Yang, P. (2015) Anxiety Levels of Children under General Anesthesia and the Degree of Cooperation Induced by Anesthesia. Journal of Nursing Management, 15, 706-707.

[18] Vagnoli, L., Caprilli, S. and Messeri, A. (2010) Parental Presence, Clowns or Sedative Premedication to Treat Preoperative Anxiety in Children: What Could Be the Most Promising Option? Pediatric Anesthesia, 20, 937-943. https://doi.org/10.1111/j.1460-9592.2010.03403.x

[19] Bumin, A.G., Yüksel, S., Ergil, J., et al. (2017) The Effect of Play Distraction on Anxiety before Premedication Administration: A Randomized Trial. Journal of Clinical Anesthesia, 36, 27-31. https://doi.org/10.1016/j.jclinane.2016.04.044

[20] Munemori, H., Ishibashi, T., Hirata, Y. and Miki, F. (1983) Nursing Management. Pre-Operative Nursing Care for Children with Congenital Heart Disease. Kango Gijutsu, 29, 601-605.

[21] Perry, J.N., Hooper, V.D. and Masiongale, J. (2012) Reduction of Preoperative Anxiety in Pediatric Surgery Patients Using Age-Appropriate Teaching Interventions. Journal Anesthesia Nursing, 27, 69-81. https://doi.org/10.1016/j.jopan.2012.01.003 